\title{
The Effects of Job Rotation Practices on Employee Development: An Empirical Study on Nurses in the Hospitals of Vellore District
}

\author{
Kokila Mohan \\ Research Associate, VIT Business school, VIT University \\ Email: koki.mohan90@gmail.com \\ Dr. S. Gomathi \\ Senior Professor, VIT Business School, VIT University, Vellore-632014, Tamilnadu, India \\ Email: sgomatthi@vit.ac.in, gommatthi@gmail.com
}

Doi:10.5901/mjss.2015.v6n1p209

\begin{abstract}
Job rotation is a job design approach widely used by many organization at various levels and departments. This job rotation is a technique followed by the organization to improve the workers performance and make them more committed towards the work. This acts as a motivating factor and helps in the employee development. Decreasing monotony in work, preparing employees to cope up with the management challenges, defining more productive positions and improving the level of knowledge \& skills in a specific field and these expectations can be achieved through job rotation practices which will increase the motivation among the employees and it has the positive effect towards motivation of employees and development. This study aims at the job rotation practices followed by the hospitals to empower the nurses in all the dimensions of workplace and helps them to provide quality service to the needy people.
\end{abstract}

Keywords: Job rotation, motivation, employee development, job skills, knowledge, interest

\section{Introduction}

Employees are the back bone for any organization, keeping an employee motivated towards a job is the crucial role of the organization. Keeping an employee interested in the job is the biggest challenge faced by the HR teams in any organization. The top management need to find the way where they can fulfil the needs of the employees and make them to be engaged in the work. There comes the best solution for the problem which is "Job Rotation". The Job rotation is a mechanism used by the employer to develop employees in a particular field. Job rotation gives the opportunity to develop employee's skills and knowledge in a variety of changing jobs. The job rotation activities are mainly followed in hospitals and banks on daily basis which helps to make their employees more enhanced in their job. Nurses are the backbone to doctors as well as the patients. Motivating the nurses is the biggest challenge faced by all renowned hospitals. It is a herculean task to make them relieved from stress as a result of their monotonous job, at this point any hospital has to think of stress relieving techniques which can overcome this challenge. Here comes the best solution to the challenge faced by the hospitals that is through "Job Rotation". Job rotation is the accessible technique for enhancing nurse's efficiency in rendering quality services to all needy people.

\section{Literature Review}

\subsection{Job Rotation}

Job rotation is a training method followed by the organization to develop the employees in various department were they can gain diversified learning of job skills for a specific period of time and job rotation is a practical approach to enrich and expand the job assignments of the employees (Seibert \& Kraimer, 2001). Therefore, job rotation is a method of job design which allows the employees to learn the job skills from various departments and eliminates the employees fatigue caused by the same kind of job assignments by changing such assignments (Richard Thackray, 1981). The challenges faced by the employees in the new assignments can encourage them to gain enthusiasm and improve their morale in the work environment (Jorgensen M, Davis et al, 2005).while implementing the job rotation in the organization the management 
should focus on the quality of individual's work experience rather than quantity of work. Then next rotation plan should be arranged according to the learning capability and adjustment time of the employees (Campion MA et al. 1994).

\subsubsection{Definition}

Job rotation is a job design and management approach in which nurses are moved between two or more jobs in a planned manner. In all the hospitals they use this job rotation technique to make nurses well-versed in all the verticals of the organization. They render services to needy people and at the same time they perform multi-tasking by handling training sessions to the training nurses, work in different departments etc.

\subsection{Employee Development}

Employee development is the important factor which influence the employee development and organization development as a whole. It acts as the motivating factor to the employees and helps them in develop themselves in the changing environment. If Proper employees are set to the job and that will lead to organizational success (Chay Hoon Lee et al.2003). Every organization relies on the employee development and leadership development for its growth and improvement. The organization need to achieve many goals with the existing employees so they need to enhance their skills and knowledge to develop them to work in this dynamic market condition (Heather R. Pierce et al. 2009). Employees are the biggest source for any organization success. Due to increase in the competition in the market managers need to concentrate on the empowerment on the employees and control them. The managers need to know about the inner and outer environment of the organization so that they can know about the functioning of it. The employees should have good skills, knowledge and capability then only they can perform their tasks perfectly and understand the organizational goals. The employee empowerment can be of direct or indirect. The direct method is providing more responsibilities to employees and indirect method is wide spread presence of groups (Rezaie Doulatabadi et al. 2011).

\subsubsection{Definition}

Cheering up the employees to acquire new or innovative skills, knowledge and views by providing learning and training facilities and avenues where such new ideas can be applied in the work area.

\section{Research Questions}

This study was processed to answer these questions:

1) Do job rotation practices followed in the organization helps in employee (nurse) development?

The job rotation activities in the organization helps the employees to expose their interest in the particular job, the developmental activities carried out by the organization ( both personal and interpersonal development), and the knowledge they gain in the job activities are framed as the hypothesis of the study and brings the evidence of the same towards the organization.

From the above literature we can find out the effects of the independent variable on the dependent variable and the hypothesis followed will help to do so:

H1: There is a significant relationship between Employee Interest and Employee Development among Nurses

H2: There is a significant relationship between Personal Development and Employee Development among Nurses Nurses

H3: There is a significant relationship between Administrative Knowledge and Employee Development among Nurses

H4: There is a significant relationship between Organization Knowledge and Employee Development among

H5: There is a significant relationship between Technical Knowledge and Employee Development among Nurses

\section{Methodology}

\subsection{Study sample and procedure}

Job rotation practices are mostly used in the service sector like banks and hospitals. So the samples are drawn from 
nurses working in the hospitals. The participants of this study were nurses in hospitals of Vellore district. Employee development is operationalized as the perceptions of the nurses towards the developmental activities followed by the hospital to develop them. The initial part of the questionnaire measured the demographic information like age, marital status, education, experience and salary. Employee development was measured using seven items which is derived from various articles. The items are employed a five-point scale ranging from 1- strongly disagree to 5- strongly agree.

Job rotation is operationalized as the perceptions of interest in these activities and the knowledge gained through job rotation. This job rotation was measured using the 18 items taken from the various articles and all the items are measured using five-point scale ranging from 1- strongly disagree to 5- strongly agree. There are 25 items listed in the questionnaire and all items are measured using five-point Likert scale. As the thumb rule says 1:5 ratio, for each item there should be 5 respondents. There are 25 items in the questionnaire and the sample size is 125. It was developed based on the past research, and modified according to the objectives of the study.SPSS (Statistical package for social science) version 17.0 was used to analyze the data.

\section{Analysis}

\subsection{Reliability analysis}

Cronbach's Alpha is the most common analysis done for measuring the internal consistency of the data. This reliability analysis is done when the items are measured with the Likert scale in the questionnaire. Nunnally and Bernstein (1994) stated that all the variables should exceed the adequate standard of reliability analysis of 0.70 . The Cronbach's Alpha is .758 which indicates that there is high internal consistency for the scales used in the questionnaire. Table 1 shows the reliability analysis results.

Table 1: Reliability analysis results

Reliability Statistics

\begin{tabular}{|c|c|}
\hline Cronbach's Alpha & N of Items \\
\hline .758 & 25 \\
\hline
\end{tabular}

\section{Results}

\subsection{Factor analysis}

The validity of the questionnaire is measured through "factor analysis" with principle component analysis which used the rotated component matrix to factor the items. Each items should load $>0.4$ and those items are factored and renamed. According to Kaiser- Meyer- Olkin .The Kaiser- Meyer- Olkin (KMO) which measures the sample adequacy was .671 while the Bartlett's Test of Sphericity was significant (App. chi-square= 1629.441, sig. is .00) which indicates the sufficient inter correlations of the factor analysis. Table 2 shows the KMO and Bartlett's Test result.

Table 2: KMO and Bartlett's Test

\begin{tabular}{|cc|c|}
\hline \multicolumn{2}{|c|}{ Kaiser-Meyer-Olkin Measure of Sampling Adequacy. } & .671 \\
& Approx. Chi-Square & 1629.441 \\
Bartlett's Test of Sphericity & Df & 300 \\
& Sig. & .000 \\
\hline
\end{tabular}

The first factor analysis with Rotated Component Matrix was done to find the items which are factored under the Employee Development construct. Table 3: shows the result of the factor analysis for the employee development construct. 
Table 3: Factor analysis of Employee Development

Factor 1: (Employee Development)

\begin{tabular}{|l|l|}
\hline Employee development issues are handled properly & .779 \\
\hline The feedback provided by the organization helps in career development & .738 \\
\hline
\end{tabular}

The second factor analysis with Rotated Component Matrix was done to find the items which are factored under the Job Rotation construct. There are five factors framed from the Job Rotation items and the factors are Interest, personal Development, Administrative Knowledge, Organization Knowledge, and Technical Knowledge. Table 4: shows the result of the factor analysis for the Job Rotation construct.

Table 4: Factor Analysis on Job Rotation

Factor 1(Employee Interest)

\begin{tabular}{|l|c|}
\hline I am interested in job rotation practice & .768 \\
\hline Job rotation is a best training and development practice followed by the organization & .744 \\
\hline Job rotation involves cross training activities & .721 \\
\hline Job rotation improves my planning and organizing skills & .587 \\
\hline Job rotation results in job satisfaction. & .502 \\
\hline
\end{tabular}

Factor 2: (Personal Development)

\begin{tabular}{|l|c|}
\hline Job rotation improves my interpersonal skills & .743 \\
\hline My self-confident level increases through job rotation practice & .684 \\
\hline Job rotation leads to succession planning & .668 \\
\hline JR improves communication network & .484 \\
\hline
\end{tabular}

Factor 3: (Administrative Knowledge)

\begin{tabular}{|l|c|}
\hline My cognitive skills get improved through job rotation & .835 \\
\hline Job rotation provides me a chance for promotion & .660 \\
\hline Through job rotation practice my leadership skills get improved & 561 \\
\hline
\end{tabular}

Factor 4: (Organization Knowledge)

\begin{tabular}{|l|l|}
\hline JR improves my knowledge of general issues in the organization & .724 \\
\hline I have role clarity before going for JR & .679 \\
\hline
\end{tabular}

Factor 5: (Technical knowledge)

\begin{tabular}{|l|l|}
\hline JR enhances knowledge of organization policies, procedures and practices & .720 \\
\hline JR helps me in understanding organizational goals & .715 \\
\hline
\end{tabular}

The results of the study shows the pattern of effect of different factor on the dependent variable (employee development).

\subsection{Correlation}

The correlation analysis is used to measure the degree of linear relationship between two variables. The correlation emphasis on the degree to which the linear model describe the relationship between the variables. It helps to identify whether two variables have positive or negative relationship and helps in finding out the direction which the variables move.

By undertaking Pearson Correlation test for analyzing significance of relationship between employee interest and employee development among nurses shows positive correlation (i.e. Pearson correlation is .371) and it infer that there is strong relationship between these variables. P-value was determined as significance $=0.00$ and because the Sig. value is $<0.05$ Null Hypothesis is rejected. Therefore, there is a significant relationship between Employee Interest and Employee Development.

For analyzing significance of relationship between Personal Development and employee development among nurses shows positive correlation (i.e. Pearson correlation is .567) and it infer that there is strong relationship between these variables (because the Pearson correlation is >.3). P-value was determined as significance $=0.00$ and because the 
Sig. value is $<0.05$ Null Hypothesis is rejected. Therefore, there is a significant relationship between Personal Development and Employee Development.

For analyzing significance of relationship between Administrative Knowledge and employee development among nurses shows positive correlation (i.e. Pearson correlation is .158) and it infer that there is weak relationship between these variables (because the Pearson correlation is <.3). P-value was determined as significance $=0.79$ and because the Sig. value is $>0.05$ Null Hypothesis is accepted. Therefore, there is no significant relationship between Administrative Knowledge and Employee Development.

For analyzing significance of relationship between Organization Knowledge and employee development among nurses shows positive correlation (i.e. Pearson correlation is .258) and it infer that there is weak relationship between these variables (because the Pearson correlation is <.3). P-value was determined as significance $=0.04$ and because the Sig. value is $<0.05$ Null Hypothesis is rejected. Therefore, there is a significant relationship between Organizational Knowledge and Employee Development.

For analyzing significance of relationship between Technical Knowledge and employee development among nurses shows positive correlation (i.e. Pearson correlation is .210) and it infer that there is weak relationship between these variables (because the Pearson correlation is <.3). P-value was determined as significance $=0.19$ and because the Sig. value is $<0.05$ Null Hypothesis is rejected. Therefore, there is a significant relationship between Technical Knowledge and Employee Development.

Table 5: Shows the results for correlation between Job Rotation practices and Employee Development

Table 5: Correlations

\begin{tabular}{|c|c|c|c|c|c|c|c|}
\hline & & EMP_DEV & INTEREST & PER_DEV & ADMIN_KNOW & ORG_KNOW & TECH_KNOW \\
\hline \multirow{3}{*}{ EMP_DEV } & Pearson Correlation & 1 & $.371^{*+*}$ & $.567^{*+2}$ & .158 & $.258^{* *}$ & $.210^{*}$ \\
\hline & Sig. (2-tailed) & & .000 & .000 & .079 & .004 & .019 \\
\hline & $\mathrm{N}$ & 125 & 125 & 125 & 125 & 125 & 125 \\
\hline \multirow{3}{*}{ INTEREST } & Pearson Correlation & $.371^{\text {t* }}$ & 1 & $.422^{*+*}$ & $.289^{* * *}$ & $.282^{*+*}$ & $.224^{*}$ \\
\hline & Sig. (2-tailed) & .000 & & .000 & .001 & .001 & .012 \\
\hline & $\mathrm{N}$ & 125 & 125 & 125 & 125 & 125 & 125 \\
\hline \multirow{3}{*}{ PER_DEV } & Pearson Correlation & $.567^{\text {t* }}$ & $.422^{* *}$ & 1 & $.211^{*}$ & .163 & .159 \\
\hline & Sig. (2-tailed) & .000 & .000 & & .018 & .069 & .077 \\
\hline & $\mathrm{N}$ & 125 & 125 & 125 & 125 & 125 & 125 \\
\hline & Pearson Correlation & .158 & $.289^{*+}$ & $.211^{\star}$ & 1 & $.233^{\text {t* }}$ & $237^{\text {t* }}$ \\
\hline \multirow[t]{2}{*}{ ADMIN_KNOW } & Sig. (2-tailed) & .079 & .001 & .018 & & .009 & .008 \\
\hline & $\mathrm{N}$ & 125 & 125 & 125 & 125 & 125 & 125 \\
\hline \multirow{3}{*}{ ORG_KNOW } & Pearson Correlation & $.258^{*+}$ & $.282^{\text {t* }}$ & .163 & $.233^{\text {*t+ }}$ & 1 & .128 \\
\hline & Sig. (2-tailed) & .004 & .001 & .069 & .009 & & .156 \\
\hline & $\mathrm{N}$ & 125 & 125 & 125 & 125 & 125 & 125 \\
\hline \multirow{3}{*}{ TECH_KNOW } & Pearson Correlation & $.210^{*}$ & $.224^{*}$ & .159 & $.237^{+*}$ & .128 & 1 \\
\hline & Sig. (2-tailed) & .019 & .012 & .077 & .008 & 156 & \\
\hline & $\mathrm{N}$ & 125 & 125 & 125 & 125 & 125 & 125 \\
\hline
\end{tabular}

\section{Discussion}

The present study designed to witness the relationship between Job Rotation and Employee Development among Nurses in Vellore District. As expected the results of the Correlation discovered that the measures of job rotation found to be positively correlated with each other. Specifically this study reveals the interest in job rotation practice, personal development. Administrative knowledge, organizational knowledge and technical knowledge are the significant factors for Employee development. The relationship between job rotation and development suggests that the employees with high interest will have high chance of getting promoted in the organization (Campion et al.1994). Which implies that the nurses get higher chance of getting better positions in the hospitals. And all other factors are also contributing towards the 
development process, were the nurses can get better knowledge in the organization specifications and policies, and it implies that job rotation also contributes towards personal development among nurses and makes them feel more empowered (Marian et al. 1995).

In summary job rotation should be employed by the hospitals in order to encourage the nurses to enrich their knowledge and skills. This could encourage the organization to have better knowledge and understanding on the need of nurses and helps them to get developed.

\section{Research Implications}

The findings from the study have several implications to both theory and practical situations. Based on the theoretical perspective, there is a positive relationship between job rotation and employee development among nurses in the hospitals. Therefore with regard to the model of employee development by Abdul Hameed et al. (2011), job rotation can be used in the organizational strategy for improving the employee's skills, knowledge and attitude and self - development.

The current study indicates that there is a positive relationship between job rotation and employee development hence it can contribute to the organizational learning activities. Were the organizational learning involves the learning process of individual and organization as a whole within the organization.

Based on the practical implication this job rotation practice is well known by the nurses in the hospitals and perform their tasks without knowing its importance. But this study concentrates on the various benefits given to the nurses through job rotation practices are clearly revealed and the HR executives can clearly understand the essentials of job rotation which can be a cheap and best training method they can follow in all type of organizations.

\section{Conclusion}

This study has provided additional insights into the relationship between the job rotation practices and Employee development especially among the nurses of the hospitals in Vellore district. It brings the clear empirical evidence that there is positive effect of job rotation on employee development activities in the hospitals. The job rotation is the mechanism were the organization provides a chance to nurses to learn many things from variety of tasks performed. Job rotation ensures that the nurses should not be stressed out with the same kind of work and being boredom in the job. Job rotation can bring competitive advantage to the organization when it is implemented accurately. The job rotation practices have positive effect on motivating nurses in performing the tasks. The positive effect on decreasing monotony, increase in knowledge, skills and competence and development of social relationships among nurses will results in motivation and it will leads to employee development. The findings suggest that job rotation is a best and cheap training method and it can be followed by any organization to provide their employees a better life by making them to work in various tasks and gain more knowledge and make them efficient in handling issues in the organization which leads a successful career of nurses.

\section{References}

Allwood, J.M. \& Lee, W.L. (2004). The impact of job rotation on problem solving skills. International Journal of Production Research, 42(5), 865-881.

Campion, M. A., Cheraskin, L. \& Stevens, M. J. (1994). Career related antecedents and outcomes of job rotation. The Academy of Management Journal, 37(6), 1518-1552.

Chay Hoon Lee \& Norman T. Bruvold, "The International Journal of Human Resource Management", Int. J. of Human Resource Management 14:6 September 2003 981-1000

Cleveland, J. N., \& Shore, L. M. (1992). Self- and supervisory perspectives on age and work attitudes and performance. Journal of Applied Psychology, 77, 469-484.

Diana S. Contino,"Leadership Competencies: Knowledge, Skills, and Aptitudes Nurses Need to Lead Organizations Effectively", 2004; 24: $52-64$

Gannon, M. J., Poole, B. A. \& Prangley, R. E. (1972). Involuntary job rotation and work Behaviour. Personnel Journal, 51, 446-448.

Huang, H. J. (1999). Job rotation from the employee's point of view. Human Resource Management, 7(1), 75-85.

Jorgensen, M. (2005). Characteristics of job rotation in the Midwest US manufacturing Sector. Ergonomics, 48(15), 1721-1733.

Karsh, B., Booske, B. C., \& Sainfort, F. (2005). Job and organizational determinants of nursing home employee commitment, job satisfaction and intent to turnover. Ergonomics, 48, 1260-1281.

Kurtulu Kaymaz, "The Effects of Job Rotation Practices on Motivation: A Research on Managers in the Automotive Organizations", Volume 1, Number 3 2010, pp. 69-85

Mobley, W. H. (1977). Intermediate linkages in the relationship between job satisfaction and employee turnover. Journal of Applied 
Psychology, 62, 237-240.

O'Connor, E. J., Rudolf, C. J. \& Peters, L. H. (1980). Individual differences and job design reconsidered: Where do we go from here? The Academy of Management Review, 5(2), 249-254.

Pierce, Heather R.; Maurer, Todd J., "Linking employee development activity, social exchange and organizational citizenship behavior", vol. 13, 3, 2009, pp.139-147

Richard I. Thackray, "The Stress of Boredom and Monotony: A Consideration of the Evidence", Psychosomatic Medicine, Vol. 43, No. 2 (April 1981)

Sara Zaniboni, Donald M. Truxillo, and Franco Fraccaroli, "Differential effects of task variety and skill variety on burnout and turnover intentions for older and younger workers", 2013

Schyns, B., \& Von Collani, G. (2002). A new occupational self-efficacy scale and its relation to personality constructs and organizational variables. European Journal of Work and Organizational Psychology, 11, 219-241

Scott E. Seibert, Maria L. Kraimer, "A social capital theory of Career success", Academy of management journal, 2001, vol. 44, No 2, p 219-237.

Susan, S. (1996). The new story about job rotation. Academy of Management Executive, 10(1), 86-87.

Truxillo, D. M., Cadiz, D. M., Rineer, J. R., Zaniboni, S., \& Fraccaroli, F. (2012). A lifespan perspective on job design: Fitting the worker to the job to promote job satisfaction, engagement, and performance. Organizational Psychology Review, 2, 340 -360. 